\title{
SYNTHESIS OF SILVER NANOPARTICLES BY CHEMICAL REDUCTION METHOD: EFFECT OF REDUCING AGENT AND SURFACTANT CONCENTRATION
}

\author{
G. Suriati ${ }^{*}$, M. Mariatti ${ }^{2}$ and A. Azizan ${ }^{2}$ \\ ${ }^{1}$ Faculty of Chemical and Natural Resources Engineering, Universiti Malaysia Pahang, \\ Lebuhraya Tun Razak, 26300 Kuantan, Pahang, Malaysia \\ ${ }^{2}$ School of Materials and Mineral Resources Engineering, Universiti Sains Malaysia, \\ Engineering Campus, 14300 Nibong Tebal, Seberang Prai Selatan, Penang, Malaysia \\ *corresponding author; suriati@ump.edu.my; \\ Tel.: 609-5492881; Fax: 609-5492022
}

\begin{abstract}
Uniform, well-dispersed, silver nanoparticles (AgNPs) were prepared by a simple chemical reduction method. The particles were synthesized via the reduction of $\mathrm{AgNO}_{3}$ by trisodium citrate and ascorbic acid as a surfactant. The resulting AgNPs were characterized by X-ray diffraction analysis, transmission electron microscopy, and scanning electron microscopy. It was found that the size of the AgNPs ranged from 35$80 \mathrm{~nm}$, with an average of $50 \mathrm{~nm}$. In this study, the effects of trisodium citrate and ascorbic acid, which act as reducing agent and surfactant respectively on the morphology of the silver nanoparticles, were investigated. It was found that the increasing concentration of trisodium citrate resulted in decreasing size of silver nanoparticles, while increasing the concentration of ascorbic acid shows the opposite effect. Moreover, the quasi-spherical shape of as-synthesized silver nanoparticles is also more uniform with the increase of trisodium citrate. Meanwhile, a slight change in particle shape from quasi-spherical to polygonal was observed as the concentrations of ascorbic acid were increased.
\end{abstract}

Keywords: Chemical synthesis; silver nanoparticles; reducing agent; surfactant.

\section{INTRODUCTION}

Metal particles having ultrafine size have received great attention due to their unusual properties that differ from bulk metal. The chemical and physical properties of the metal nanoparticles are dependent on their size as well as their structure, shape and size distribution. Therefore, control over the size and size distribution is crucial and is often achieved by varying the synthesis methods, reducing agents and stabilizers [1]. Precise control of such factors allows the desired physical and chemical changes to the nanoparticles. Generally, metal nanoparticles can be prepared in two different ways, i.e., physical and chemical methods. In the physical method, preparation of metallic nanoparticles includes laser ablation [2], evaporation/condensation [3], and UV irradiation [4]. Although physical methods are able to produce particles in nano sizes, only reports on chemical methods can be found abundantly in the literature. The main chemical method is the reduction of metal ions in solution (chemical reduction method) [5]. In recent years, many chemical methods for the synthesis of silver nanoparticles have been reported including the polyol method [6] and the liquid-liquid method [7]. 
However, chemical reduction is the most commonly used, due to its simplicity. This technique also enables variation in the molar concentration of the reactant, dispersant and feed rate of reactant in order to produce silver nanoparticles with controlled particle sizes, shapes and particle size distribution. The selection of an appropriate reducing agent is also a crucial factor, as the size, shape and particle size distribution strongly depend on the nature of the reducing agent. The introduction of a reducing agent causes the reduction of metal precursor. Reduction of metal salts requires adjustment of the reactivity of the reducing agent to the redox potential of the metal. During the synthesis process, if the reaction rate is too fast, rapid formation of a large amount of metal nuclei will occur and result in particles that are too small. On the other hand, agglomeration of particles will take place if the reaction rate is too slow. Moreover, the choice of the surfactant is critical since it determines the stability, solubility, reactivity, dispersibility and even the size and shape of the nanoparticles during the synthesis $[5,6]$. The present study describes a simple, low-cost, and partially green method, to synthesize silver nanoparticles. This synthesis method is considered partially green as it uses ascorbic acid which is one form of vitamin C. It has also been widely used as a reducing agent in synthesis processes. However, there is no work reporting the use of ascorbic acid as a surfactant, especially in the synthesis of silver particles. Therefore, in the present study, ascorbic acid has been used as a surfactant, rather than as a reducing agent, in order to prevent the aggregation of metal particles. The effects of the combined trisodium citrate and ascorbic acid on the AgNPs produced were characterized by XRD, whilst the particle morphology and size were observed by TEM.

\section{EXPERIMENTAL}

In this study, silver nitrate $\left(\mathrm{AgNO}_{3}\right)$ was used as a starting material while trisodium citrate $\left(\mathrm{C}_{6} \mathrm{H}_{5} \mathrm{O}_{7} \mathrm{Na}_{3}\right)$ and ascorbic acid $\left(\mathrm{C}_{6} \mathrm{H}_{8} \mathrm{O}_{6}\right)$ were used as the reducing agent and surfactant, respectively. The concentrations of trisodium citrate and ascorbic acid were varied in order to observe the effect of these parameters especially on the size and morphology of the silver nanoparticles. The experimental technique, with some modification to the existing method reported by Dadosh [8], has been applied for this study. In detail, $80 \mathrm{ml}$ of $\mathrm{AgNO}_{3}$ was first heated to $60^{\circ} \mathrm{C}$ and was then added (with vigorous stirring) to $20 \mathrm{ml}$ of a $\mathrm{C}_{6} \mathrm{H}_{5} \mathrm{O}_{7} \mathrm{Na}_{3}$ and $\mathrm{C}_{6} \mathrm{H}_{8} \mathrm{O}_{6}$ solution that was pre-heated to $60^{\circ} \mathrm{C}$. The mixture was then stirred for 20 minutes. After that, the heating was stopped and the solution was cooled at room temperature with continuous stirring. The assynthesized AgNPs colloid was characterized by XRD (model D5000 Siemens Diffractometer) with $0.15405 \mathrm{~nm} \mathrm{Cu} \mathrm{K \alpha}$ radiation. The size and morphology of the Ag nanoparticles produced were studied by TEM (model Philips CM12 equipped with Docu Version 3.2 image analysis system).

\section{RESULTS AND DISCUSSION}

In this study, AgNPs were prepared by the chemical reduction method. During the synthesis process, the reductant $\left(\mathrm{C}_{6} \mathrm{H}_{5} \mathrm{O}_{7} \mathrm{Na}_{3}\right)$ directly reduced $\mathrm{Ag}^{+}$to generate metallic $\mathrm{Ag}$ atoms. The produced $\mathrm{Ag}$ atoms then acted as nucleation centres and catalysed the reduction of the remaining metal ions present in the solution. The coalescence of atoms led to the formation of metal clusters, which are normally stabilized by ligands, surfactants, or polymers [9]. In this study, it is believed that the ascorbic acid which acted as a surfactant was adsorbed onto the surface of the Ag atoms, and thus prevented 
the nanoparticles from agglomerating. At the beginning of the process, the newly reduced Ag atoms acted as the nuclei of the nanoparticles. With further processing time, these nuclei grew continuously. Indication of the formation of AgNPs was observed by change in the solution colour. During this process, the solution went through a number of colour changes from light yellow $\rightarrow$ yellow $\rightarrow$ greenish, before it stabilised. These colour changes indicate the growth of the AgNPs. In this process, the reaction can be expressed as follows [10]:

$$
4 \mathrm{Ag}^{+}+\mathrm{C}_{6} \mathrm{H}_{5} \mathrm{O}_{7} \mathrm{Na}_{3}+2 \mathrm{H}_{2} \mathrm{O} \rightarrow 4 \mathrm{Ag}^{0}+\mathrm{C}_{6} \mathrm{H}_{5} \mathrm{O}_{7} \mathrm{H}_{3}+3 \mathrm{Na}^{+}+\mathrm{H}^{+}+\mathrm{O}_{2}
$$

Figure 1 shows the photographs of the final colour of the solution after synthesis processes that involved different amounts of trisodium citrate dihydrate-reduced silver nanoparticles. As the concentration of trisodium citrate dihydrate increased from $4.0 \mathrm{mM}$ to $8.0 \mathrm{mM}$, a brownish to light yellow colour could be observed, which is characteristic of the surface plasmon resonance (SPR). The colour of metal nanoparticles such as silver nanoparticles depends on the shape and size of the nanoparticles and the dielectric constant of the surrounding medium. According to Zielińska, Skwarek [11], only electrons with free electrons, especially $\mathrm{Au}, \mathrm{Ag}, \mathrm{Cu}$ and the alkali metals, possess plasmon resonance in the visible spectrum, which gives rise to such colours.

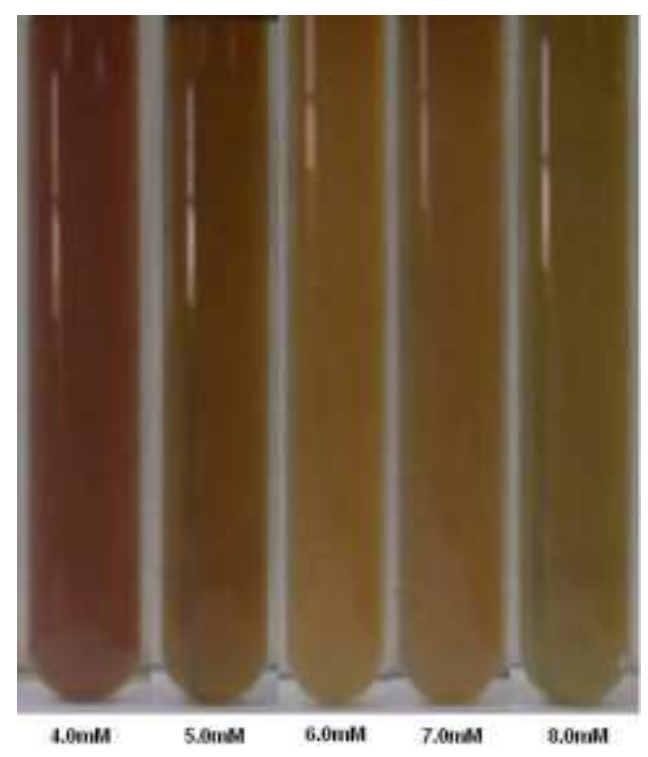

Figure 1. The final colour of Ag nanoparticles solution as a function of trisodium citrate dihydrate concentrations.

The TEM images in Figure 2 shows that at all concentrations of trisodium citrate dihydrate, the particles are quasi-spherical with the presence of other shapes, e.g. polygons, and they are well-dispersed. The resultant histograms which represent the size distributions of the particles were obtained using Image $\mathbf{J}$ software of at least 100 particles. By referring to the result in Figure 2, the average sizes of the silver nanoparticles show a decreasing trend, from $38.53 \mathrm{~nm}$ at $4.0 \mathrm{mM}$ to $36.32 \mathrm{~nm}$ at 8.0 $\mathrm{mM}$ of trisodium citrate dihydrate. As the concentration of trisodium citrate dihydrate increases from $4.0 \mathrm{mM}$ to $8.0 \mathrm{mM}$, the particle size histograms of the silver nanoparticles also show a narrowing of the particle size distribution from $20-65 \mathrm{~nm}$ to $20-50 \mathrm{~nm}$. 


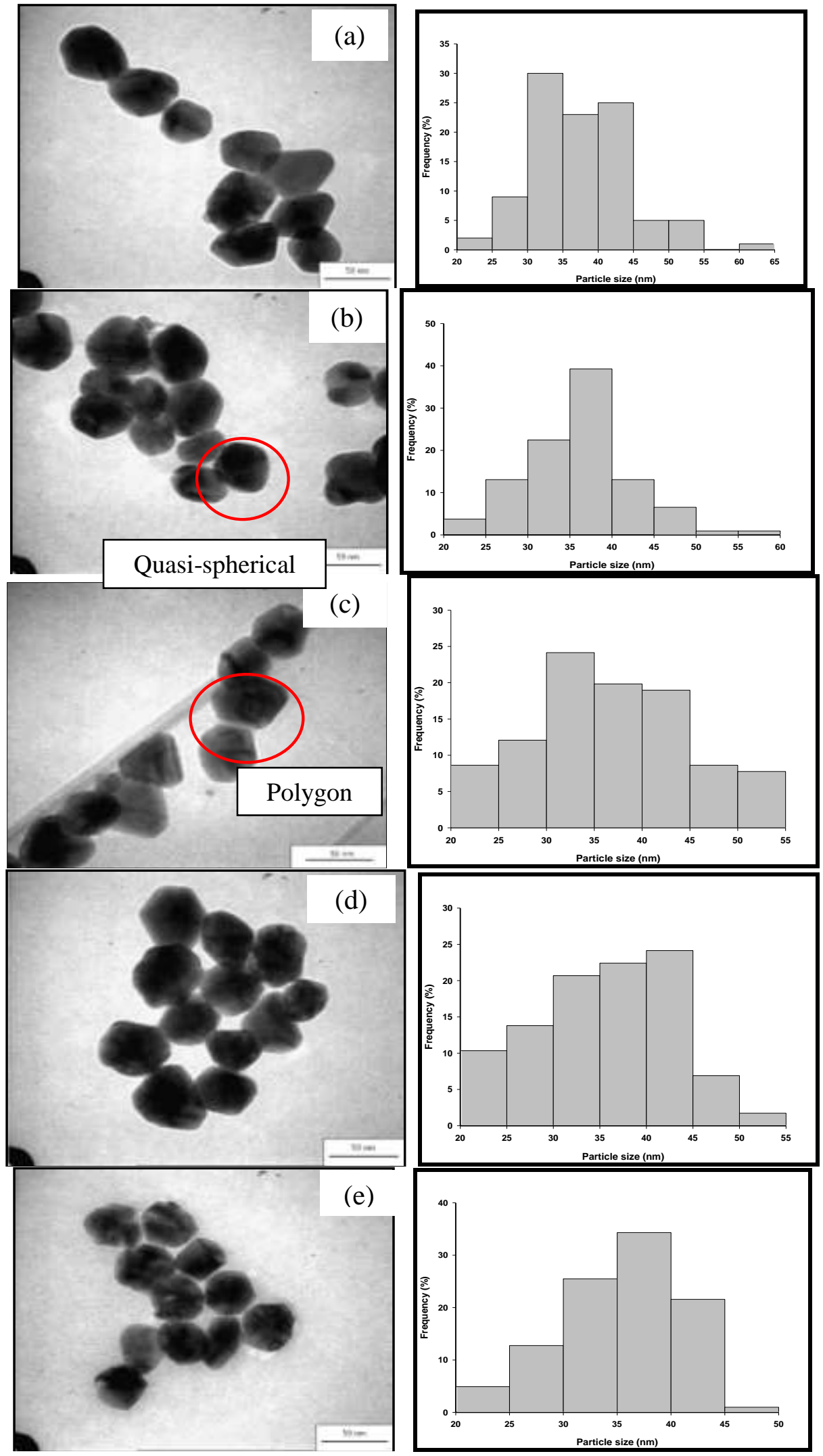

Figure 2. TEM micrographs and size distribution histograms of silver nanoparticles at different concentrations of trisodium citrate dehydrate: (a) $4.0 \mathrm{mM}$ (avg. $38.53 \mathrm{~nm}$ ); (b) $5.0 \mathrm{mM}$ (avg. $37.22 \mathrm{~nm}$ ); (c) $6.0 \mathrm{mM}$ (avg. $37.24 \mathrm{~nm}$ ); (d) $7.0 \mathrm{mM}$ (avg. $36.44 \mathrm{~nm}$ ); (e) $8.0 \mathrm{mM}$ (avg. $36.32 \mathrm{~nm})$. 
The reason for this phenomenon could be the fact that the rate of reaction is directly proportional to the concentration of reactant according to the law of mass action. Therefore, it can be suggested that with increasing trisodium citratedihydrate concentration, the rate of reaction increases. As the rate increases, the silver ions are consumed faster, thus leaving less possibility for particles size growth. Photographs of silver nanoparticles colloid obtained at different concentrations of ascorbic acid (1.0 $\mathrm{mM}, 2.0 \mathrm{mM}, 3.0 \mathrm{mM}$ and $4.0 \mathrm{mM}$ ) are shown in Figure 3. It can be clearly seen that the final colour of the silver colloids changes from light yellow to greenish as the concentration of ascorbic acid is increased from $1.0 \mathrm{mM}$ to $4.0 \mathrm{mM}$. It should be noted that higher concentrations of stabilizing agent could also cover up the nanoparticles, thus reducing the dispersivity of the nanoparticles in solution, which could be indicated by the formation of larger sizes of silver nanoparticles. The colour changes of the solution, which are related to the increase in particle size, were also proved by the TEM images in Figure 4.

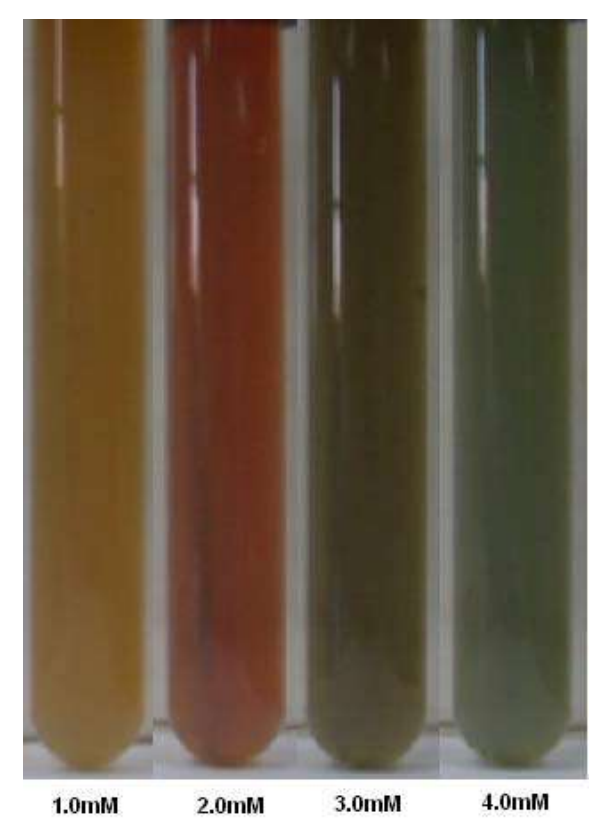

Figure 3. The final colour of Ag nanoparticles solution as a function of ascorbic acid concentrations.

From the TEM images in Figure 4, it can be clearly seen that the average size of silver nanoparticles increased with increasing concentration of ascorbic acid from 1.0 $\mathrm{mM}$ to $4.0 \mathrm{mM}$. The average sizes of the silver nanoparticles prepared at $1.0 \mathrm{mM}, 2.0$ $\mathrm{mM}, 3.0 \mathrm{mM}$ and $4.0 \mathrm{mM}$ of ascorbic acid were $37.24 \mathrm{~nm}, 43.04 \mathrm{~nm}, 45.85 \mathrm{~nm}$ and $47.28 \mathrm{~nm}$, respectively. The histograms of particle distribution in Figure 4 also reveal that the size distribution of the silver nanoparticles is relatively wide, with particles as large as $75 \mathrm{~nm}$ being found in the samples prepared at $4.0 \mathrm{mM}$ of ascorbic acid. Changes in shape from quasi-spherical to polygonal could also be observed, especially at $4.0 \mathrm{mM}$ of ascorbic acid. Since ascorbic acid is also a mild reducing agent, it is believed that the remaining $\mathrm{Ag}^{+}$ions continued to form $\mathrm{Ag}^{0}$ atoms, and adhered to the surface of existing $\mathrm{Ag}$ particles, so changing the morphology of the product from quasi-spherical to polygonal shape. 


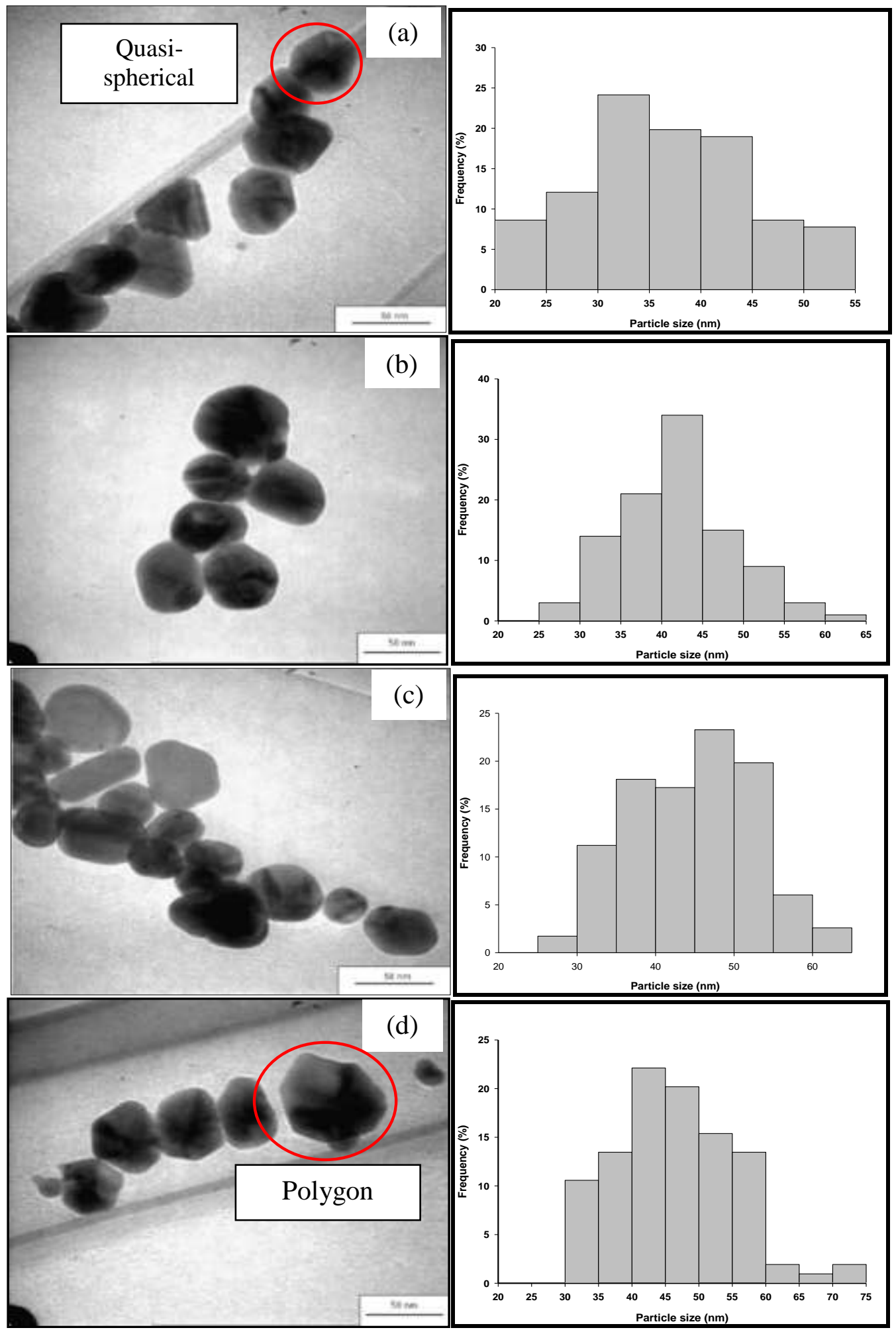

Figure 4. Final colour of Ag nanoparticles solution, TEM micrographs and size distribution histograms prepared at different concentrations of ascorbic acid: (a) $1.0 \mathrm{mM}$ (avg. $37.24 \mathrm{~nm}$ ); (b) $2.0 \mathrm{mM}$ (avg. $43.04 \mathrm{~nm}$ ); (c) $3.0 \mathrm{mM}$ (avg. $45.85 \mathrm{~nm}$ ); (d) $4.0 \mathrm{mM}$ (avg. $47.28 \mathrm{~nm}$ ). 
It seems plausible that the ascorbic acid was able to kinetically control the growth rates of various faces by selectively adsorbing onto those faces. Due to the acidic properties of ascorbic acid, adding a high concentration of ascorbic acid subsequently lowers the $\mathrm{pH}$ of the solution. As reported by Guo, Gan [12], the acidic condition results in the formation of flaky, dendritic or non-uniform shapes which are not suitable for the preparation of spherical silver powder. This argument suggests that the morphology observed for the sample prepared at $4.0 \mathrm{mM}$ of ascorbic acid is in contrast with the sample prepared at lower ascorbic acid concentrations. Figure 5 shows the representative X-ray diffractogram plotted of the as-synthesized AgNPs. The obtained Bragg reflections index (111), [13], (220), and (311) which corresponds to the FCC structure also shows that the as-synthesized AgNPs were essentially crystalline. However, it can also be observed that the peaks are substantially broadened, indicating that the material is composed of very small silver crystallites. XRD patterns of the nanoparticles exhibit several size-dependent features, leading to anomalous peak positions, heights, and widths. Previous work by Oliveira, Ugarte [14] indicates that nano-sized metal particles are expected to present a lattice contraction due to high surface pressure, and a distinctive non-crystalline atomic arrangement.

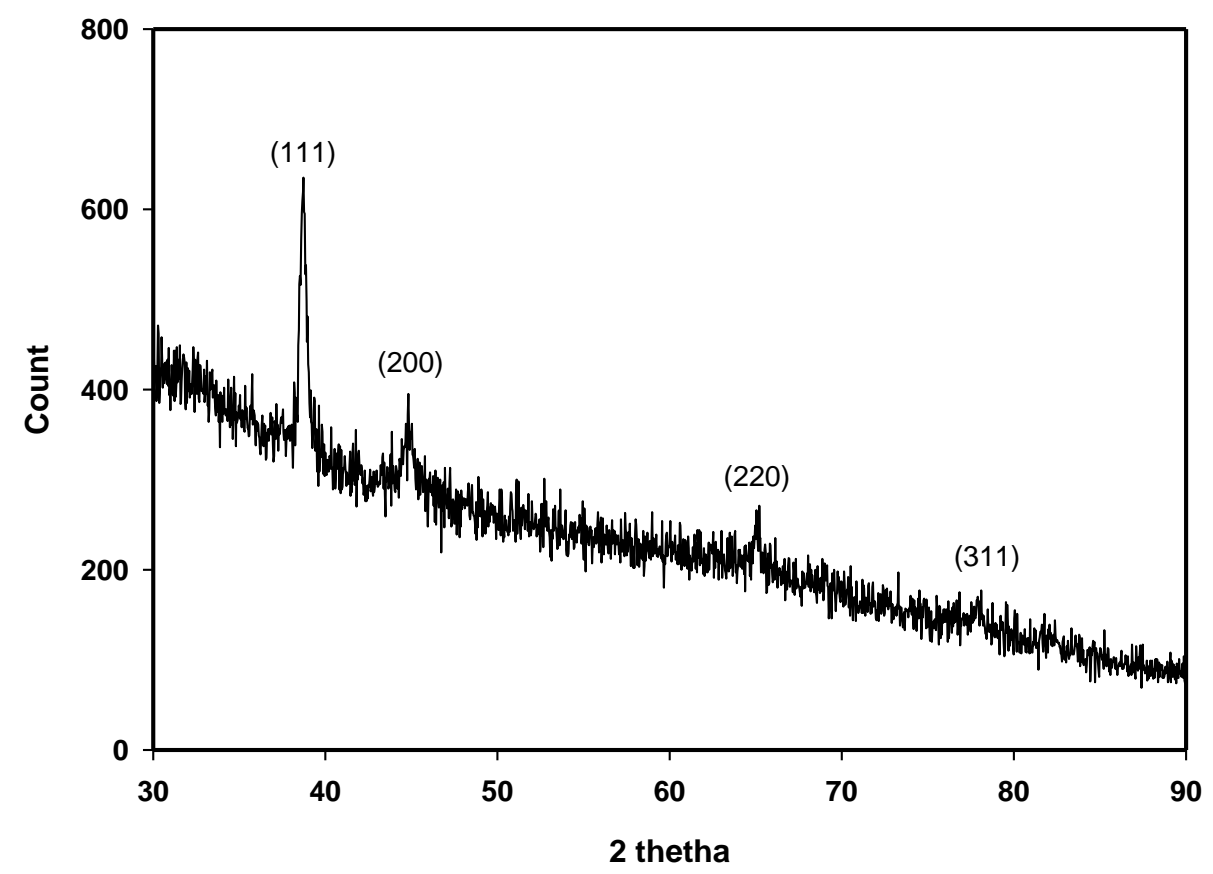

Figure 5. XRD pattern of as-synthesized AgNPs.

\section{CONCLUSIONS}

Fine dispersion and narrow size distribution of silver nanoparticles can be acquired by a simple, and partly green chemical reduction method. It is believed that ascorbic acid played a significant role in dispersing the particles whilst lowering the degree of particle agglomeration. The formulated ECA with better particle distribution of the assynthesized AgNPs showed a remarkable improvement in electrical conductivity as compared to commercial AgF and AgNPs. 


\section{ACKNOWLEDGEMENTS}

The authors would like to thank the Ministry of Higher Education Malaysia (MOHE), the National Science Foundation (NSF), and Research Grant (RDU121413) for financial support and facilities.

\section{REFERENCES}

[1] Abou El-Nour KM, Eftaiha A, Al-Warthan A, Ammar RA. Synthesis and applications of silver nanoparticles. Arabian journal of chemistry. 2010;3:13540.

[2] Tarasenko N, Butsen A, Nevar E, Savastenko N. Synthesis of nanosized particles during laser ablation of gold in water. Applied surface science. 2006;252:4439-44.

[3] Jung JH, Cheol Oh H, Soo Noh H, Ji JH, Soo Kim S. Metal nanoparticle generation using a small ceramic heater with a local heating area. Journal of aerosol science. 2006;37:1662-70.

[4] Darroudi M, Ahmad MB, Zak AK, Zamiri R, Hakimi M. Fabrication and characterization of gelatin stabilized silver nanoparticles under UV-light. International journal of molecular sciences. 2011;12:6346-56.

[5] Chou K-S, Ren C-Y. Synthesis of nanosized silver particles by chemical reduction method. Materials Chemistry and Physics. 2000;64:241-6.

[6] Taguchi A, Fujii S, Ichimura T, Verma P, Inouye Y, Kawata S. Oxygen-assisted shape control in polyol synthesis of silver nanocrystals. Chemical Physics Letters. 2008;462:92-5.

[7] Cai M, Chen J, Zhou J. Reduction and morphology of silver nanoparticles via liquid-liquid method. Applied surface science. 2004;226:422-6.

[8] Dadosh T. Synthesis of uniform silver nanoparticles with a controllable size. Materials letters. 2009;63:2236-8.

[9] Manno D, Filippo E, Di Giulio M, Serra A. Synthesis and characterization of starch-stabilized Ag nanostructures for sensors applications. Journal of NonCrystalline Solids. 2008;354:5515-20.

[10] Šileikaitė A, Prosyčevas I, Puišo J, Juraitis A, Guobienè A. Analysis of silver nanoparticles produced by chemical reduction of silver salt solution. Materials Science. 2006;12:287-91.

[11] Zielińska A, Skwarek E, Zaleska A, Gazda M, Hupka J. Preparation of silver nanoparticles with controlled particle size. Procedia Chemistry. 2009;1:1560-6.

[12] Guo G, Gan W, Luo J, Xiang F, Zhang J, Zhou H, et al. Preparation and dispersive mechanism of highly dispersive ultrafine silver powder. Applied Surface Science. 2010;256:6683-7.

[13] Manning R, Ewing, J. (2009). .RACQ vehicles technologies. Temperatures in cars survey. RACQ Vehicles Technologies. 2009:1-21.

[14] Oliveira MM, Ugarte D, Zanchet D, Zarbin AJ. Influence of synthetic parameters on the size, structure, and stability of dodecanethiol-stabilized silver nanoparticles. Journal of colloid and interface science. 2005;292:429-35. 